\title{
MANUAL DE IDENTIDADE VISUAL: desusos, tendências e desafios.
}

\author{
Marco A. Mazzarotto Filho \\ Universidade Tecnológica Federal do Paraná (UTFPR) \\ marcomazzarotto@gmail.com
}

\begin{abstract}
Resumo: O presente trabalho tem como objetivo identificar e analisar os elementos que atualmente compõe manuais de identidade visual desenvolvidos para empresas privadas e demais organizações. Com esta análise pretende-se avaliar quais aspectos ainda são relevantes, quais precisam ser repensados e quais seriam as novas necessidades e desafios a serem contemplados. Para isso, utiliza-se como método a revisão de literatura em duas obras dessa temática aliada a análise de vinte manuais de identidade visual, sendo dez de instituições brasileiras e dez internacionais. Os resultados demonstram que são poucos os itens em desuso, mas que existem relevantes novas tendências e desafios a serem contemplados.
\end{abstract}

Palavras-chave: Identidade visual, Manual da marca, Novas tendências.

\begin{abstract}
This study aims to analyze the elements that are currently used in brandbooks. This analysis aims to assess which aspects are still relevant, which need to be rethought and what are the new needs and challenges to be addressed. Bibliographic research in two reference books of the the field was applied, followed by the analysis of 20 real brandbooks found over the internet. The results show that there are few unused items, but there are important new trends and challenges to be addressed.
\end{abstract}

Key words: Visual Identidy, Brandbook, news trends.

\section{INTRODUÇÃO}

O presente artigo tem como objetivo traçar um panorama atual dos elementos inseridos em manuais de identidade visual. $O$ foco da análise está primeiramente em identificar quais são esses elementos, a freqüência no seu uso e avaliar sua atual relevância. Em seguida, a análise busca identificar lacunas existentes no conteúdo desses manuais frente as novas necessidades do mercado, sugerindo novos elementos que possam ajudar a contemplá-las.

\section{MÉTODO}

O método aplicado neste trabalho consistiu de uma pesquisa bibliográfica seguida por uma pesquisa documental. A pesquisa bibliográfica pautou-se na revisão 
de literatura de duas obras nacionais sobre o tema: Peón (2009) e Munhoz (2009). 0 objetivo desta etapa foi identificar os elementos que devem compor um manual de identidade visual segundo a literatura.

Com base nessa listagem de elementos que deveriam ser contemplados, partiuse para a segunda etapa, composta pela análise de manuais existentes. O objetivo dessa etapa foi identificar quais elementos sugeridos pela literatura foram efetivamente utilizados pelos manuais da amostra selecionada, com qual freqüência foram usados e se existiam elementos novos inseridos nos manuais e que não foram anteriormente identificados na pesquisa bibliográfica.

A amostra (Quadro 1) definida para a pesquisa documental foi de vinte manuais, sendo dez de instituições brasileiras e dez internacionais. Além disso, os demais critérios para seleção foram a disponibilidade dos arquivos na web, a diversidade nas áreas de atuação da instituição, e a data de desenvolvimento (que não poderia ser superior a 10 anos).

Quadro 1 - Amostra de manuais de identidade visual analisados.

\begin{tabular}{|l|l|l|l|}
\hline Manuais internacionais & Ano & Manuais nacionais & Ano \\
\hline Carrefour & 2009 & Copobras & $2012^{*}$ \\
\hline Dove & 2006 & Cruzeiro & $2012^{*}$ \\
\hline Edinburgh & 2005 & Escoteiros do brasil & $2010^{*}$ \\
\hline International Paralympic Committee & 2013 & FIAT & $2007^{*}$ \\
\hline Jamie Oliver & Pós 2005* & Governo Brasileiro & 2011 \\
\hline Nike Football & 2009 & GVT & $2011^{*}$ \\
\hline Renault & 2007 & Inmetro & $2010^{*}$ \\
\hline Skype & $2011^{*}$ & PUC-RS & 2009 \\
\hline University of Northern Colorado & 2011 & RIO+20 & $2011^{*}$ \\
\hline Wallmart & 2009 & SAMU & Pós $2004^{*}$ \\
\hline * Data estimada pelo autor com base em pesquisas de notícias relacionadas ao lançamento da nova
\end{tabular}

\section{O MANUAL DE IDENTIDADE VISUAL SEGUNDO A LITERATURA}

O manual de identidade visual é uma publicação com normas e diretrizes para o uso, em diversos meios de comunicação, de uma determinada marca (SEBRAE-SP, 2004). Para Peón (2009), o manual é a fase final do projeto de um sistema de identidade visual, e consiste em um documento prevendo a implantação deste sistema por terceiros, sem a necessidade de consulta posterior aos designers envolvidos.

$\mathrm{Na}$ literatura nacional sobre esse tema, existem duas obras de referência que listam e explicam quais devem ser essas normas e diretrizes a serem inseridas no manual de identidade. São os trabalhos de Peón (2009) e Munhoz (2009). Enquanto o primeiro aborda o projeto de identidade visual como um todo, o segundo é focado apenas no desenvolvimento do manual.

No quadro 2, são apresentados as listas de elementos recomendados por cada uma das autoras. O elementos colocados na mesma linha de cor do quadro são considerados como equivalentes por este trabalho. É relevante salientar que ambas autoras não definem todos esses itens como obrigatórios ou únicos, afirmando que cada projeto deve avaliar quais são os elementos relevantes dentro do seu contexto. 
Quadro 2 - Recomendações da literatura para os elementos do manual de identidade visual

\begin{tabular}{|c|c|}
\hline Munhoz (2009) & Peón (2009) \\
\hline \multicolumn{2}{|l|}{ Introdução / Objetivo } \\
\hline \multicolumn{2}{|l|}{ Identificação } \\
\hline \multicolumn{2}{|l|}{ Briefing } \\
\hline \multicolumn{2}{|l|}{ Garantia } \\
\hline \multicolumn{2}{|l|}{ Conceito } \\
\hline \multicolumn{2}{|l|}{ Princípios } \\
\hline \multirow[t]{5}{*}{ Versões da marca } & Marca prioritária \\
\hline & Marca horizontal ou vertical \\
\hline & Logotipo isolado \\
\hline & Símbolo isolado \\
\hline & Versão audiovisual (em forma de story-board) \\
\hline Grade de construção / modulação & Malhas de construção \\
\hline Tipografia padrão & Padrão tipográfico \\
\hline Cores institucionais & Padrão cromático \\
\hline Tamanho mínimo de aplicação & Reduções máximas \\
\hline $\begin{array}{l}\text { Área de interferência visual / Aplicação em fundo } \\
\text { com textura }\end{array}$ & Campo de proteção das assinaturas \\
\hline \multirow[t]{2}{*}{ Versão monocromática / Aplicação em uma cor } & Elementos primários em monocromia / traço \\
\hline & Elementos primários em monocromia / meio tom \\
\hline \multirow{3}{*}{$\begin{array}{l}\text { Versão em negativo / Aplicação em fundo escuro } \\
\text { ou colorido }\end{array}$} & Elementos primários em fundos escuros \\
\hline & Elementos primários em outline \\
\hline & Elementos primários com inclusão de grafismo \\
\hline Assinaturas & $\begin{array}{l}\text { Elementos primários com inclusão da atividade } \\
\text { fim }\end{array}$ \\
\hline \multicolumn{2}{|l|}{ Endereços } \\
\hline Proibições & Utilizações vetadas \\
\hline \multicolumn{2}{|l|}{ Folha síntese / INFO } \\
\hline Aplicação em papelaria básica & Aplicações em papelaria \\
\hline \multicolumn{2}{|l|}{ Modelo de ficha técnica / Pedido de orçamento } \\
\hline \multicolumn{2}{|l|}{ Modelo de autorização de produção } \\
\hline \multicolumn{2}{|l|}{ Modelo de ordem de serviço } \\
\hline Outras aplicações & Outras aplicações \\
\hline
\end{tabular}

Fonte: Elaborado pelo autor, com base na pesquisa realizada.

Comparando os elementos sugeridos por cada uma das autoras, é possível identificar duas grandes diferenças estruturais nas recomendações para o desenvolvimento do manual:

- Bases do projeto: As bases do projeto são as informações referentes ao histórico, descrição e valores da instituição e sua marca, e que foram levantados e aplicados no decorrer do projeto do sistema de identidade visual. Peón (2009), mesmo afirmando e defendendo a importância do uso desses dados no projeto, não menciona a sua inserção no manual. Já Munhoz (2009) defende que estas informações devem constar na primeira parte do documento, no item denominado "Briefing".

- Diretrizes gerais de linguagem visual: Nas diretrizes listadas por Peón (2009) constam apenas aspectos bem objetivos e técnicos do sistema de identidade, sendo constituídos por instruções precisas. No trabalho de Munhoz (2009), além dessas instruções técnicas objetivas, também constam dois itens um pouco mais generalistas, que apresentam a linguagem visual da marca de forma mais aberta, são elas os itens "Conceito" e "Princípios". Com base neles, é possível entender um 
pouco melhor qual a lógica de funcionamento da linguagem visual da marca, o que facilita a tarefa de criar novas peças que não estejam completamente especificadas no manual.

\section{ANÁLISE DOS MANUAIS SELECIONADOS}

O ponto de partida para análise dos manuais foi a relação de elementos elencada no quadro 2. Porém, conforme a análise avançou, surgiu a necessidade de, além de inserir novos campos para elementos não previstos pela literatura, alterar os nomes e/ou subdividir os itens para melhor se adequarem a realidade encontrada nos manuais selecionados.

O instrumento final de análise é apresentado no quadro 3. Ele conta com cinqüenta e sete elementos divididos em quatro grupos. Devida a grande quantidade de itens, não cabe a este trabalho explicar todos em detalhes. Os mais relevantes e as novidades serão abordados posteriormente durante as análises, para os outros, se faz necessária a consulta ao trabalhos de Peón (2009) e Munhoz (2009).

Quadro 3 - Relação dos itens analisados nos manuais selecionados.

\begin{tabular}{|c|c|}
\hline Número de páginas & C.17 Cores: Pantone \\
\hline A. Elementos iniciais & C.18 Cores: RGB \\
\hline A.1 Introdução / Objetivo & C.19 Cores: Hexadecimal \\
\hline A.2 Sumário & C.20 Cores: RAL \\
\hline A.3 Identificação autoria & C.21 Cores: HSK \\
\hline A.4 Contato com os responsáveis & C.22 Cores: Vinil \\
\hline A.5 Glossário & C.23 Cores: Automotivas \\
\hline A.6 Garantia & C.24 Cores: Imobiliárias \\
\hline B. Sobre a instituição & C.25 Cores: Tecido \\
\hline B.1 Identificação da empresa & C.26 Tipografias utilizadas na marca \\
\hline B.2 Histórico/Descrição da instituição & C.27 Alfabeto institucional \\
\hline B.3 Público-alvo & C.28 Área de proteção da marca \\
\hline B.4 Valores & C.29 Malha de construção \\
\hline B.4 Evolução da identidade visual & C.30 Elementos acessórios \\
\hline C. A marca e seus elementos & D. Uso do sistema \\
\hline C.1 Conceito & D.1 Redução máxima: Impresso. \\
\hline C.2 Versão prioritária & D.2 Redução máxima: Digital. \\
\hline C.3 Versão alternativa (horizontal ou vertical) & D.3 Aplicação sob fundo escuro \\
\hline $\begin{array}{l}\text { C. } 4 \text { Versões com assinatura, apenas símbolo ou } \\
\text { apenas logotipo }\end{array}$ & D.4 Aplicação sob fundo claro \\
\hline C.5 Versão Mono Traço - P\&B & D.5 Aplicação sob fundo colorido uniforme \\
\hline C.6 Versão Mono Traço - Outras cores & D.6 Aplicação sob fundo inconstante \\
\hline C.7 Versão Mono - Escala Cinza & D.7 Diretrizes para a linguagem visual \\
\hline C.8 Versão Mono Meio-tom - Outras cores & D.8 Posicionamento da marca \\
\hline C.9 Versão Cor em Negativo & D.9 Diretrizes para o uso de imagens \\
\hline C.10 Versão Mono Traço em Negativo & D.10 Diretrizes para o uso da tipografia \\
\hline C.11 Versão Mono Meio-tom em Negativo & D.11 Especificação de tipografia impressa e digital \\
\hline C.12 Versão sem gradiente & D.12 Tom de voz \\
\hline C.13 Versão outline & D.13 Usos proibidos \\
\hline C.14 Versões em cores alternativas & D.14 Templates \\
\hline C.15 Versões adaptadas para produção & D.15 Exemplos de peças gráficas \\
\hline C.16 Cores: CMYK & D.16 Especificações técnicas para produção \\
\hline
\end{tabular}

Fonte: Elaborado pelo autor, com base na pesquisa realizada. 


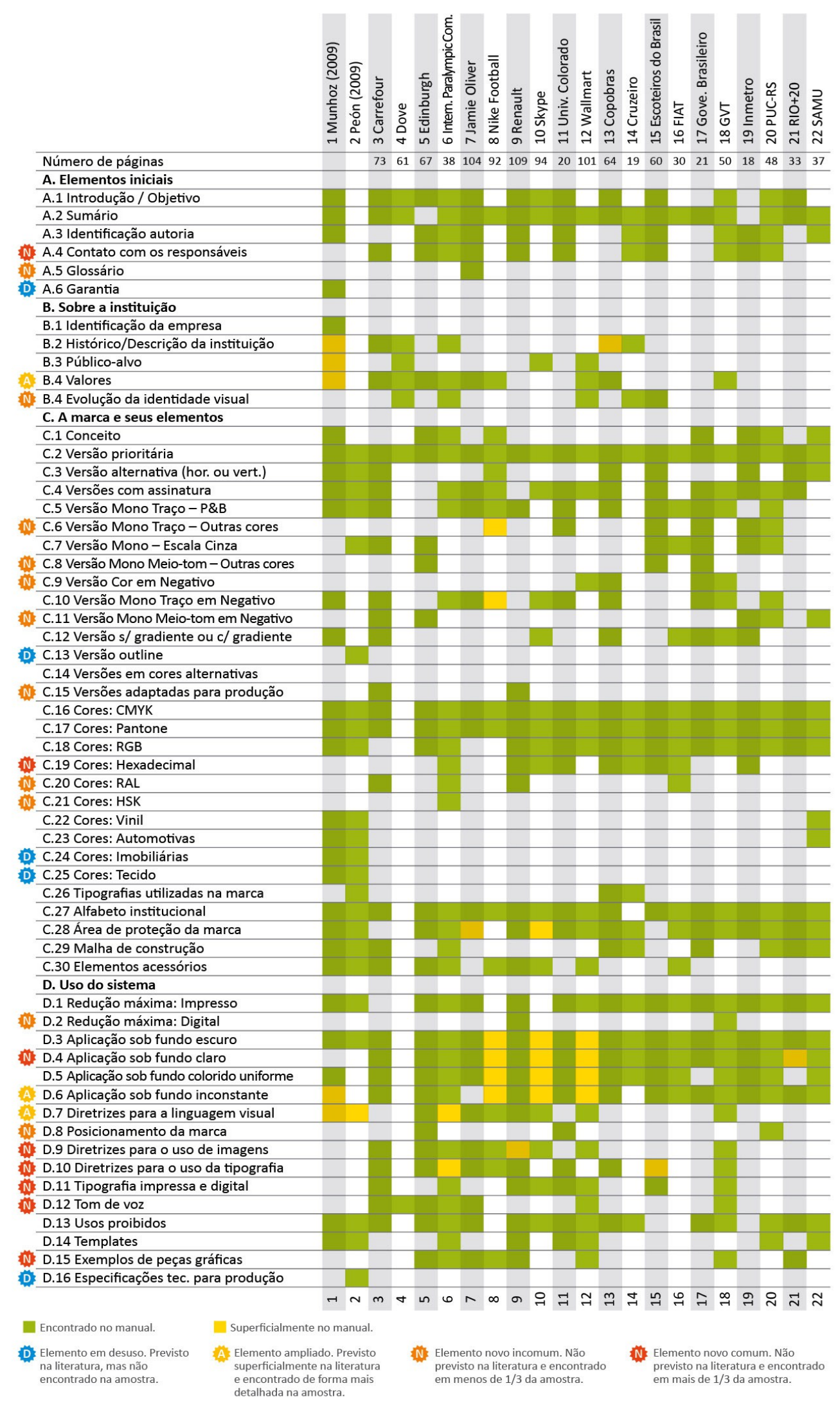

Figura 1 - Resultado da aplicação do instrumento de análise.

Fonte: Elaborado pelo autor, com base na pesquisa realizada. 
Na figura 1, são apresentados os resultados da aplicação do instrumento de análise nos vinte manuais selecionados. O quadro também incorpora as recomendações feitas por Peón (2009) e Munhoz (2009), permitindo a comparação entre as sugestões da literatura e o que foi encontrado na amostra. Para a representação dos resultados, foram utilizadas duas formas de marcação: quadrados e estrelas. Os quadrados representam a incidência do item no exemplar analisado, sendo da cor verde para representar sua ocorrência de forma plena e a cor amarela quando a ocorrência é muito superficial ou pouco explícita. Já as estrelas na lateral esquerda do quadro apontam as correlações entre literatura e manuais reais: na cor azul para representar as diretrizes sugeridas, mas não encontradas na amostra; na cor amarela para representar os elementos tratados com maior profundidade do que a sugerida na literatura; e duas variações de laranja para apontar os elementos novos, o mais claro representando os itens de baixa ocorrência (menos que $1 / 3$ ) e o mais escuro representando os itens de maior ocorrência (superior a 1/3). A análise de cada um desses grupos é apresentada a seguir.

\subsection{Elementos em desuso}

Cinco diretrizes propostas pela literatura não foram encontradas na amostra analisada, são elas:

- A.6 Garantia: Proposta por Munhoz (2009), essa diretriz especifica uma espécie de contrato entre designer, instituição e fornecedores, isentando o designer de responsabilidades nos resultados da aplicação do sistema caso as diretrizes previstas não sejam consideradas corretamente. É um elemento interessante para ser inserido em manuais desenvolvidos para empresas contratantes, mas parece fazer pouco sentido para manuais desenvolvidos internamente pela próprias empresas, o que é o caso de grande parte da amostra.

- C.13 Versão Outline: Sugerida por Peón (2009), a ocorrência da previsão da versão apenas em contornos da marca não parece ser uma prática recorrente. Sua existência como recomendação permanente em uma lista de diretrizes para manuais pode ser portanto reconsiderada.

- C.24 Cores: Imobiliária e C.25 Cores: Tecido: Esses itens são referentes a definição das cores de tintas latex, acrílica ou esmalte para uso em ambientes, assim com das cores para tecidos de uniformes e outras peças nesse material. Apesar de ficar claro a relevância dessas informações para diversos tipos de instituições, a sua utilização não foi encontrada. Uma hipótese para isso é que o acesso de designers gráficos a esses catálogos pode ser mais restrita.

- D.16 Especificações técnicas para produção: Referente a especificação de materiais, formatos, número de cores e acabamentos das peças gráficas, essa recomendação feita por Peón (2009) não foi encontrada. Nos manuais onde são especificados templates (peças gráficas prontas), sua utilização seria muito importante para garantir a conformidade da produção com o projetado pelo designer.

Entre esses itens, o C.13 pode ser considerado como uma diretrizes pouco relevante e desnecessária para a maior parte dos manuais. Já os itens A.6, C.24, C.25 e D.16, apesar de não encontrados na análise, poderiam trazer benefícios aos projetos se fossem incorporados. 


\subsection{Elementos ampliados}

Três diretrizes propostas pela literatura de forma superficial foram encontradas na amostra analisada com um nível de relevância maior que o previsto:

- B.4 Valores: Munhoz (2009) defende a inserção desse tipo de informação no item denominado por ela como "Briefing". Porém, na forma breve e puramente textual como é apresentado, não condiz com a relevância que nove dos manuais analisados atribuíram a esse aspecto. Na figura 2, por exemplo, é apresentada uma das nove páginas sobre essa diretriz encontrada no manual da Nike Football.

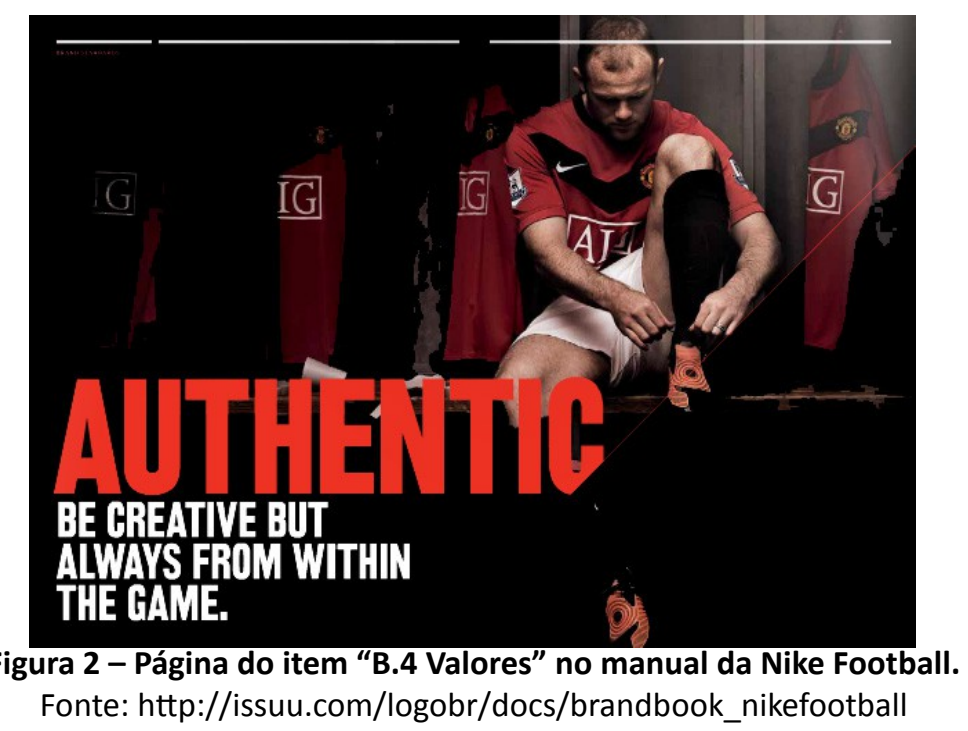

- D.6 Aplicação sob fundo inconstante: Refere-se a aplicação da marca sob uma imagem com muita variação entre tons claros e escuros. Munhoz (2009) trata desse item de forma pouco apropriada, já que o aborda como aplicação sob textura, o que é superficial, já que a textura pode ser predominantemente clara ou escura, e não necessariamente inconstante. Além disso, a autora vincula essa aplicação com a descrição da área de proteção da marca. A aplicação sob fundo inconstante pode ou não utilizar de um box nas proporções dessa área, mas não obrigatoriamente. Quatorze dos manuais analisados descrevem de forma clara como tratar essa aplicação, enquanto outros três tratam de forma menos explícita, com essas aplicações sendo encontradas em exemplos de peças gráficas.

- D.7 Diretrizes para linguagem visual: Munhoz (2009), no seu item "Princípios", aborda brevemente algumas linhas gerais da linguagem visual da identidade. Já Peón (2009) cita o item "Especificações de layout" como um elemento acessório, mas não descreve em detalhes do que se trata. Diferente do item D.14 Templates, que define peças gráficas prontas, a diretriz linguagem visual aponta quais são os caminhos para o desenvolvimento de novas peças. Um exemplo é apresentado na figura 3, onde pode-se observar uma página do manual da Skype que aponta como devem ser construídas as nuvens para serem utilizadas como elementos de apoio em layouts. 


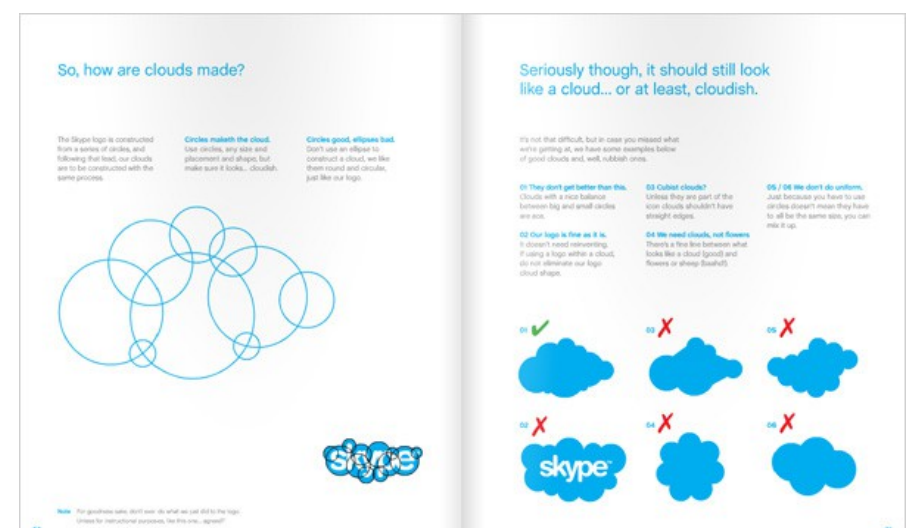

Figura 3 - Página do item D.7 Diretrizes para a linguagem visual no manual da Skype. Fonte: http://issuu.com/bondo/docs/skype_brand_book_-_look

\subsection{Elementos novos}

Como pode ser observado na figura 1, é grande a ocorrência de novos elementos não previstos pela literatura. Novamente, não há espaço neste artigo para abordar cada um em profundidade, porém, é possível agrupar boa parte destas diretrizes em dois grupos de tendências relevantes:

- Aspectos digitais: A presença de uma marca em mídias digitais é uma realidade praticamente inevitável atualmente. Por essa razão, percebe-se uma tendência nos manuais analisados de propor diretrizes específicas para essa mídia. São elas: a definição de uma redução mínima em pixels para monitores (D.2), a presença da especificação de cores no código hexadecimal (C.19) utilizado pela linguagem HTML/CSS e a especificação de tipografias específicas para mídia digitais (D.11).

- Compreensão maior da linguagem da marca e seu uso: Na obra de Peón (2009), e um pouco menos na de Munhoz (2009), as diretrizes referentes ao uso do sistema estão mais focadas em apresentar peças gráfica prontas (templates) do que em demonstrar qual é a linguagem da marca e como ela deve ser usada para novas criações. Porém, em boa parte dos manuais analisados, percebe-se uma forte tendência em apresentar diretrizes mais genéricas e flexíveis, que longe de entregar templates, pretendem explicar como as linguagens visual e verbal da marca devem ser trabalhadas. O item D.7 Diretrizes para linguagem visual visto anteriormente está relacionado a esse grupo, que contém também os seguintes novos elementos:

- D.8 Posicionamento da marca: Recomendações sobre como posicionar a marca em um layout.

- D.9 Diretrizes para o uso de imagens: Recomendações de como selecionar ou produzir imagens fotográficas dentro da linguagem definida pela marca e como aplicá-las em peças gráficas. A figura 4 apresenta um exemplo retirado do manual do International Paralympic Committee, que aponta claramente que as deficiências físicas dos atletas não pode ser recortadas das fotos. 
Photos. Editorial Misuses.
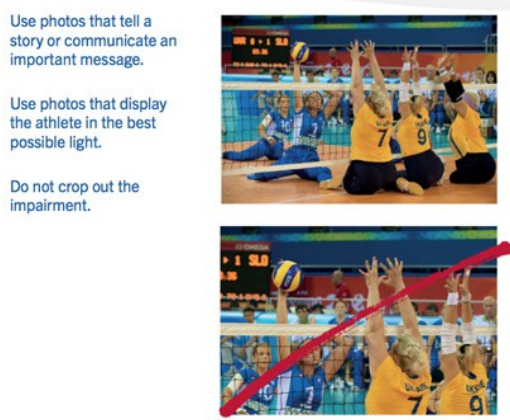
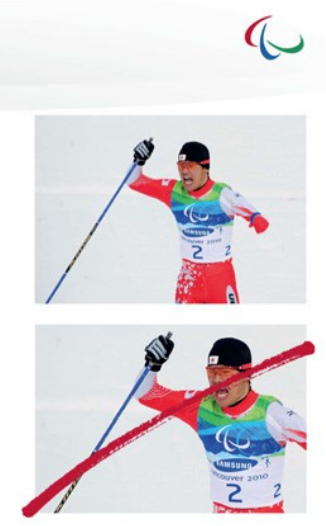

Figura 4 - Página do item "D.9 Diretrizes para o uso de imagens" no manual IPC.

Fonte: www.paralympic.org/sites/default/files/document/130201151815660_ipc_13_brandbook_130201_s.pdf

- D.10 Diretrizes para o uso da tipografia (figura 5): Além de só especificar uma lista de tipografias, esse elemento elenca recomendações de onde e como cada tipografia pode ser aplicada.

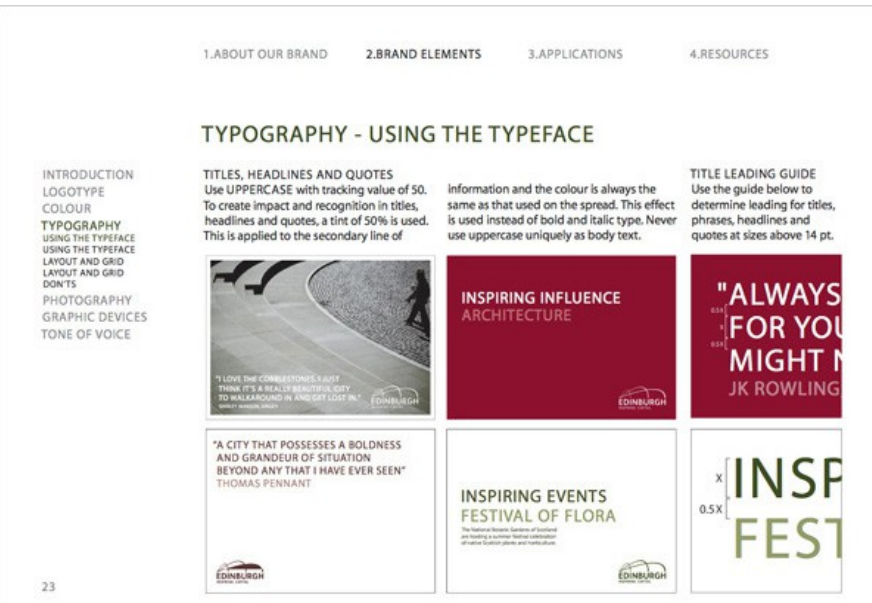

Figura 5- Página do item "D.10 Diretrizes para o uso da tipografia" no manual da cidade de Edinburgh. Fonte: www.edinburghbrand.com/PDF/Brand\%20Guidelines.pdf

- D.12 Tom de voz (figura 6): Aborda recomendações de como as mensagens devem ser criadas, tanto quanto ao seu conteúdo, como a forma de redação dos textos. 


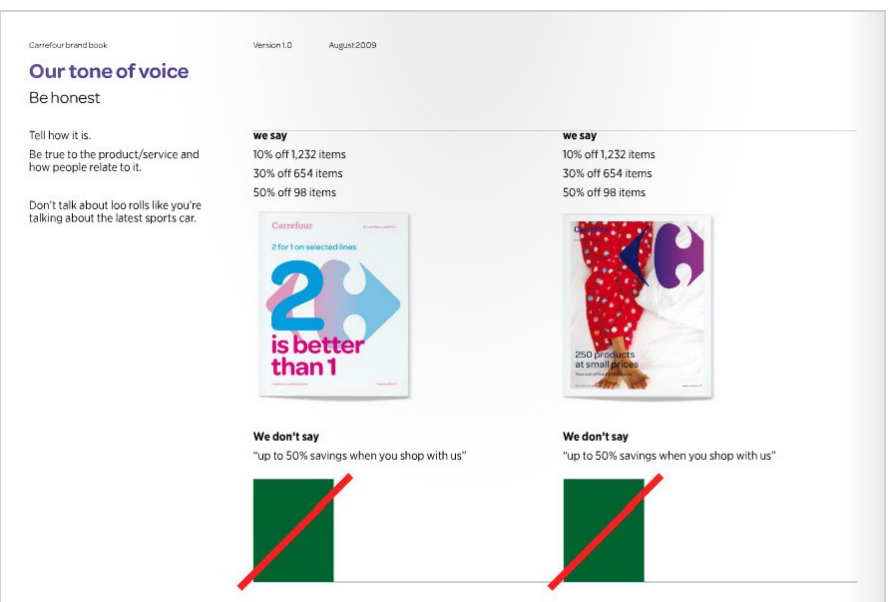

Figura 6 - Página do item "D.12 Tom de voz" no manual do supermercado Carrefour. Fonte: issuu.com/logobr/docs/carrefour_brand_book

\subsection{Análise dos elementos "clássicos".}

Como elementos "clássicos" considera-se aquelas diretrizes sugeridas pela literatura e que também estão presentes na maior parte dos manuais analisados, sendo portando aspectos já consolidados desse documento. Porém, isso não significa que não existam ressalvas e pontos interessantes a serem discutidos sobre o seu uso. Alguns desses aspectos são debatidos a seguir:

- Versões da marca: No instrumento de análise aplicado, os itens C.2 a C.13 correspondiam a variações na forma de aplicar a marca. Destes, os itens mais encontrados são os referentes a versões da marca acompanhadas por assinaturas ou só com o símbolo ou só logotipo, além das versões positivo monocromáticas P\&B. Nenhuma das demais versões chegou a ser contemplada por mais de $50 \%$ da amostra. É evidente que uma marca não é obrigada a ter todos os tipos de versões, porém, mesmo nesse caso, sugere-se pelo menos que essas versões sejam abordadas como uso proibidos. Caso contrário, não fica claro se a ausência de especificação significa que não é possível utilizar essa variação ou se ela apenas não foi especificada.

- Aplicação em diferentes fundos: Relacionada ao item anterior, a especificação de aplicação em diferentes fundos (D.3 a D.6) deve apresentar quais são os tipos de fundo onde a aplicação é permitida e como isso deve ser feito. A simples existência de uma lista ampla de versões da marca não corresponde uma equivalência direta a aplicação em diferentes fundos, ainda assim eles precisam ser especificados e explicados. Um bom exemplo disso pode ser percebido quando da existência de três versões da marca em negativo: colorida, $P \& B$ e escala de cinza. Em qual tipo de fundo escuro cada uma deve ser utilizada? $\mathrm{Na}$ figura 1 , os itens marcados em amarelo nestas diretrizes são aqueles que não especificaram explicitamente como utilizar cada fundo, mas que nos exemplos de aplicação acabaram mostrando indiretamente usos nesse sentido.

- Malha de construção: Dos itens "clássicos" de uma manual de identidade visual, a malha de construção é definitivamente um dos que mais gera debate sobre a sua necessidade atual. Munhoz (2009) defende que sua presença é fundamental para entender a lógica construtiva da marca, mesmo enfatizando 
que hoje, tanto como método mais comum tanto quanto método mais recomendável, as marcas sempre são reproduzidas a partir de seus arquivos digitais, sem a necessidade de utilizar a malha de construção para refazê-la. Logo, se não deveria ser permitido reconstruir a marca manualmente, a não ser por seus arquivos digitais, será que ainda se faz necessária a manutenção desse elemento? Em texto presente no manual da Copobras, essa contradição fica muito mais evidente: "A malha construtiva serve como guia para os casos de reprodução à mão. É proibido o redesenho ou reprodução da logotipia a partir de outras fontes que não as digitais. Caso seja necessário, solicite os arquivos ao Marketing.". Ou seja, ao mesmo tempo que aponta-se como é a malha para reprodução manual, o seu uso é terminantemente proibido. Dos manuais analisados, 6 nacionais, e apenas 2 internacionais, mantiveram esse elemento.

\subsection{A presença digital das marcas: novos desafios}

Ao analisar os resultados encontrados, aparentemente o novo grande desafio a ser abordado nos projetos de identidade visual, e respectivamente em seus manuais, é como deve ser a presença da marca em meios digitais. Como já foi comentado, essa é uma das tendências identificadas, mesmo assim, ainda existem várias questão não previstas para esta mídia pelos manuais analisados:

- Redução mínima digital: Os monitores apresentam resolução diferente que materiais impressos, logo é imprescindível avaliar também qual a redução mínima nesses meios. Nos manuais analisados, apenas dois fizerem isso.

- Favicon: Um favicon é uma imagem de apenas 16x16 pixels utilizadas para representar um site na barra de endereços, abas e favoritos dos navegadores (DUBOST, 2005). Uma redução direta da marca para essas dimensões dificilmente irá gerar resultados legíveis, sendo portanto importante que os novos manuais de identidade já contemplem uma versão para esse ícone.

- Avatares: Um avatar é uma imagem geralmente quadrada utilizada para representar o perfil de uma pessoa ou instituição em redes sociais. As dimensões reduzidas e o formato predominantemente quadrado podem provocar dificuldades para a aplicação de algumas marcas. Estratégias específicas devem ser previstas pelos manuais nesses casos.

- Templates e diretrizes de layout para redes sociais: Nos manuais analisados, alguns apresentavam templates ou diretrizes para o layout de sites e assinaturas de e-mail, mas nenhum apresentou peças específicas para customização do layout de redes sociais.

- Tom de voz em redes sociais: Como já foi relatado, a definição de diretrizes sobre o que e como escrever é uma nova tendência nos manuais de identidade. Porém, será que essas diretrizes atualmente presentes nos manuais são completamente válidas também para o uso em redes sociais, ou são necessárias diretrizes específicas para a linguagem desse meio?

\section{CONCLUSÃO}

Ao término deste trabalho, algumas conclusões foram alcançadas na mesma proporção em que novas questões acabaram sendo levantadas. Do ponto de vista da relação entre recomendações da literatura e resultado das análises, é possível perceber que cinco das diretrizes sugeridas não são utilizadas na prática. De maneira inversa, o 
número de novas práticas adotadas pelo mercado é bem superior ao de itens sugeridos pela obras acadêmicas: são dezenove novos itens, além da ampliação na complexidade de três. Nesse sentido, o que se pode concluir é que diferente de estar mudando radicalmente seu conteúdo, os novos manuais de identidade estão ampliando o espectro de suas diretrizes para abranger novas necessidades.

Entre essas novas necessidades, as mais notáveis se encontram em dois grupos: as referentes as diretrizes da presença digital da marca, e as referentes a uma especificação mais flexível e abrangente de como utilizar a linguagem visual e verbal da marca corretamente para criar novas peças gráficas. Dessas, a primeira parece ser a que concentra os maiores desafios, já que ainda há vários aspectos não contemplados pelos manuais.

A partir deste panorama, alguns novos problemas de pesquisas podem ser identificados. Neste trabalho, o foco em cada diretriz sugerida foi pouco qualitativo e descritivo, já que identificou apenas se ela existia ou não, sem uma preocupação em explicá-la ou avaliar qual seria a melhor forma de utilizá-la. Uma trabalho centrado em descrever melhor cada elemento do manual, assim como sugerir guidelines para o seu uso correto, parece agora necessário. Além disso, todos aspectos referentes a presença digital das marcas também representam um campo vasto ainda pouco explorado.

\section{REFERÊNCIAS}

DUBOST, Karl. How to Add a Favicon to your Site. W3C, 2005. Disponível na internet por http em: <www.w3.org/2005/10/howto-favicon>. Acesso em 12 mai. 2014.

MUNHOZ, Daniella Michelena. Manual de identidade visual: Guia para construção de manuais. Rio de Janeiro: 2AB. 2009.

PEÓN, Maria Luísa. Sistemas de identidade visual. Rio de Janeiro: 2AB, 2009. 4o Edição.

SEBRAE-SP. ABC do Design. São Paulo, 2004.

\section{Endereço eletrônico do manuais analisados:}

Carrefour: http://issuu.com/logobr/docs/carrefour_brand_book

Dove: http://pt.slideshare.net/BetoLima/dove-brandbook-14349051

Edinburgh: http://www.edinburghbrand.com/PDF/Brand\%20Guidelines.pdf

IPC: http://www.paralympic.org/sites/default/files/document/130201151815660_ipc_13_brandbook_130201_s.pdf

Jamie Oliver: http://issuu.com/bellfrog/docs/jamie-oliver-frv-brand-guidelines

Nike Football: (http://issuu.com/logobr/docs/brandbook_nikefootball) /

Renault: http://www.gsbil.se/foretaget/graphic_guidelines_english_id2405.pdf

Skype: http://issuu.com/bondo/docs/skype_brand_book__look

University of Nothern Colorado: http://www.unco.edu/universityrelations/pdf/unc_gid_style_guide_v3_11.pdf

Wallmart: http://www.walmartempowerswomen.org/wp-content/uploads/2011/04/walmart_brand_guidelines.pdf

Copobras: www.grupocopobras.com.br/pdfs/BrandBook_Copobras_V6.pdf

Cruzeiro: www.cruzeiro.com.br/imagem/manual_de_marca_cruzeiro.pdf

Escoteiros do brasil: www.escoteiros.org.br/arquivos/marca/manual_de_identidade_visual.pdf

FIAT: www.logotypes101.com/guidelines/Fiat_in_portuguese_.pdf

Governo Brasileiro: http://www.secom.gov.br/orientacoes-gerais/publicidade/manual-do-uso-da-marca-do-governo-federal

Inmetro: www.inmetro.gov.br/imprensa/pdf/manual_novamarcainmetro.pdf

PUC-RS: www3.pucrs.br/pucrs/manuais/identidade_visual.pdf

Rio+20 : http://www.rio20.gov.br/documentos/logomarca-e-diretrizes-de-uso/manual-do-selo-da-rio-20/at_download/manual-doselo-da-rio-20.pdf

SAMU: http://sna.saude.gov.br/download/Manual\%20de\%20Implantacao\%20do\%20SAMU.pdf 